\title{
Perfil sensorial de estudantes da primeira série do ensino fundamental: análise e comparaçáo com o desempenho escolar
}

\author{
Fernanda de Burgos Rocha ${ }^{a}$, Alessandra Bonorandi Dounis ${ }^{b}$ \\ aBacharel em Terapia Ocupacional, Universidade Estadual de Ciências da Saúde de Alagoas - UNCISAL, \\ Maceió, AL, Brasil \\ bProfessora Auxiliar da Faculdade de Terapia Ocupacional, Universidade Estadual de Ciências da Saúde de \\ Alagoas - UNCISAL, Maceió, AL. Especialista em Tecnologia Assistiva, Faculdade de Ciências Médicas de \\ Minas Gerais - FCMMG, Belo Horizonte, MG, Brasil
}

\begin{abstract}
Resumo: Introdução: Para que uma criança se desenvolva e manipule o ambiente, é necessário perceber o meio de forma adequada. O ser humano percebe o ambiente em que se encontra através dos sentidos. Para manipular o ambiente, o homem deve captar as informações do ambiente através dos órgãos dos sentidos, decodificar tais informações, processá-las, integrá-las e interpretá-las para, então, agir sobre o meio de forma adequada. Em caso de dificuldades no processamento ou interpretação das informações sensoriais, essas resultarão em dificuldades de aprendizagem. Objetivo: comparar os resultados do perfil sensorial com as notas dos estudantes do primeiro ano do ensino fundamental com idade entre 6 e 8 anos para observar a relação entre a qualidade do processamento sensorial e o desempenho escolar. Metodologia: Estudo transversal de análise descritiva. Resultados: Os dados indicam que há alta incidência de alterações sensoriais que interferem na intensidade do tônus muscular e na manutenção da postura. As informações visuais são as que apresentam melhor qualidade de processamento, enquanto o processamento de informações vestibulares e orais são os mais deficientes. Foi observado, por fim, que crianças que apresentam processamento sensorial nos níveis de Desempenho típico e Diferença provável tendem a apresentar melhor desempenho escolar. Conclusão: o processamento sensorial interfere no desempenho acadêmico mas não é o único preditor de bom resultado escolar. As informações vestibulares apresentam maior número de alterações em seu processamento sensorial.
\end{abstract}

Palavras-chave: Perfil Sensorial, Baixo Rendimento Escolar, Transtornos de Aprendizagem.

\section{Sensory profile of first grade students: analysis and comparison with school performance}

\begin{abstract}
Introduction: Children must adequately perceive their environment before they can actually develop and manipulate it. Human beings perceive their environment through their senses. To manipulate this environment, we must capture information through our sense organs and decode, process, integrate and interpret the pieces of information, so that we can act adequately in our environment. Difficulties to process or interpret sensory information will result in learning impairment. Objective: To compare the Sensory Profile results with the scores of first grade students aged between 6 and 8 years old; to observe the relation between sensory processing quality and school performance. Methods: This is a descriptive cross-sectional study. Results: Results indicate high incidence of sensory problems that interfere in the quality of muscular tonus and body posture. Visual information presented the highest processing quality, while vestibular and oral information presented the lowest processing
\end{abstract}

Autor para correspondência: Fernanda de Burgos Rocha, Universidade Estadual de Ciências da Saúde de Alagoas, Rua Dona Marieta Lages, $\mathrm{n}^{\circ}$ 61, apt 02, Farol. Maceió - Alagoas, CEP 57050-130, Maceió, AL, Brasil, e-mail: fernandadeburgos@ hotmail.com

Recebido em 5/9/2011; $1^{\text {a }}$ Revisão em 28/2/2012; $2^{\text {a }}$ Revisão em 18/4/2012; $3^{\text {a }}$ Revisão em 18/6/2012; Aceito em 27/6/2012. 
quality. Finally, it was possible to observe that children who present sensory processing at Typical Performance and Probable Difference scores tend to present the best academic achievement. Conclusion: Sensory processing interferes in academic achievement, but this is not the only factor that predicts good school scores. The highest number of changes presented is related to vestibular information.

Keywords: Sensory Profile, Underachievement, Learning Disorders.

\section{Introdução}

A terapeuta ocupacional A. J. Ayres foi, em 1972, pioneira nos estudos a respeito do processamento sensorial. Baseada em teorias sobre a organizaçáo do sistema nervoso central (SNC) realizou diversos estudos para descobrir como as crianças organizavam as informações sensoriais e como o processamento sensorial evoluía durante a vida (DUNN, 1999; WATLING; DEITZ; WHITE, 2001; MAILLOUX; PAHRAM, 2001; OLIVEIRA, 2005; GRACIANI; MOMO; SILVESTRE, 2007; MAGALHÃES, 2008).

Para que haja resposta a determinado estímulo sensorial, esse estímulo deve ser captado pelos receptores apropriados, que transformam a informação em impulsos elétricos. O impulso elétrico é enviado através dos nervos à medula espinhal e, consequentemente, ao tronco encefálico. No tronco encefálico, cada informaçáo passa por um processo primário de decodificaçáo, integração com as informaçóes provenientes dos demais sentidos, organização e interpretação. Após essa primeira interpretação das informaçôes sensoriais, elas são enviadas para o córtex cerebral, onde ocorre uma interpretação aprimorada das informaçôes, a decisão sobre qual ação efetuar em resposta e o planejamento motor da ação que responderá ao estímulo recebido, até que finalmente sejam enviados os comandos para a execução da resposta ao estímulo sensorial. Quanto mais organizadas e claras forem as informaçôes enviadas da regiáo subcortical para o córtex cerebral, mais organizadas e eficientes serão as respostas a tais informaçôes. Com isso, Ayres (2005) concluiu que, aprimorando o processamento das informaçóes vestibulares e somatossensoriais (todas processadas em nível de tronco cerebral e tálamo, regiôes subcorticais), consequentemente facilitaria-se o processamento de informaçóes mais complexas, permitindo a realização de funçôes motoras e cognitivas de forma mais eficiente (MAILLOUX; PAHRAM, 2001; DUARTE, 2005; OLIVEIRA, 2005; BODISON et al., 2006; GRACIANI; MOMO; SILVESTRE, 2007; WHITE et al., 2007; MAGALHÃES, 2008).
Alguns conceitos de grande importância desenvolvidos durante as pesquisas de A. J. Ayres foram os de nutriçáo/dieta sensorial e respostas adaptativas. A nutrição/dieta sensorial se refere à importância do contato diário com estímulos que favoreçam a organização do indivíduo visando melhor desempenho na realizaçáo de suas atividades. A autora defende que a melhor maneira de facilitar o processamento, organização e interpretação das informaçôes sensoriais nas regióes subcorticais ou corticais consiste em oferecer à criança o mesmo tipo de estímulo que ela precisa aprender a processar e utilizar, respeitando seus limites de aceitação e assimilação a esse estímulo e, sempre que necessário, administrando o contato com outros estímulos que tenham efeito desorganizador. Ayres (2005) afirma que a busca da criança pelo estímulo deve ser espontânea e não forçada pelo terapeuta ou pela família e destaca ainda a importância de a família estar a par do tipo de alteraçáo que seu filho apresenta, considerando-se que os pais têm papel de destaque no momento de "dosar" o tipo de estímulo que a criança encontra em diversos ambientes. $\mathrm{O}$ conceito de respostas adaptativas, por sua vez, refere-se ao uso das informaçóes sensoriais de forma adequada, para que haja melhora no desempenho. Sempre que a criança é confrontada com uma nova situação, ela precisa fazer uso das informaçóes sensoriais oferecidas durante a situação para se adaptar à ela. $\mathrm{O}$ fruto do processamento e uso das informações sensoriais é uma resposta adaptativa, que pode manifestar-se de modos diversos (como fazer a descarga de peso adequada para não cair da bicicleta ou aumentar o tônus dos membros superiores para carregar um objeto pesado). Uma nova resposta adaptativa a determinada demanda é sempre melhor que a resposta adaptativa anterior a essa mesma demanda e acontece de forma espontânea, permitindo a aprendizagem e/ou aperfeiçoamento de novas habilidades ou funçôes (AYRES, 2005; WATLING; DEITZ; WHITE, 2001; MAILLOUX; PAHRAM, 2001; DUARTE, 2005; OLIVEIRA, 2005; GRACIANI; MOMO; SILVESTRE, 2007; WHITE et al., 2007; MAGALHÃES, 2008). 
À medida que o processamento sensorial contribui para as aprendizagens motoras e cognitivas, estimula e facilita as aprendizagens acadêmicas. Segundo Ayres (2005), o período desde o nascimento até os 7 anos de idade representa o momento crucial para a integração sensorial. Isso se deve à dois fatores: maior receptividade cerebral às sensaçóes e maior capacidade de organização dessas informaçóes. Esse é, portanto, o período em que as funçóes sensório-motoras consolidam-se e tornam-se a base para habilidades intelectuais mais avançadas (AYRES, 2005; BURKE; MAILLOUX, 2000; MAILLOUX; PAHRAM, 2001; OLIVEIRA, 2005; BODISON et al., 2006; GRACIANI; MOMO; SILVESTRE, 2007). Segundo Ayres (2005), Bodison et al. (2006) e Graciani, Momo e Silvestre (2007), o processamento adequado das informaçôes sensoriais permite a maturação de reflexos e de mecanismos posturais durante o início da vida do bebê. Essas aquisiçóes, por sua vez, permitirão que a criança perceba o mundo a sua volta e, finalmente, explore-o e aprenda com ele. Assim, enquanto durante a primeira infância a criança faz uso das informaçóes sensoriais para conhecer a si, ao mundo e aos outros, durante a segunda infância o desenvolvimento motor ocorre com grande velocidade, requerendo sempre o uso das informaçôes sensoriais e estimulando ao mesmo tempo uma exploração mais eficiente delas (BURKE; MAILLOUX, 2000; WATLING; DEITZ; WHITE, 2001; MAILLOUX; PAHRAM, 2001; DUARTE, 2005; OLIVEIRA, 2005; BODISON et al., 2006; GRACIANI; MOMO; SILVESTRE, 2007; WHITE et al., 2007).

Caso algum aspecto relacionado ao processamento sensorial ocorra de forma inadequada, a criança pode deparar-se com situaçôes estressantes durante atividades que deveriam ser cotidianas, corriqueiras ou automáticas. A criança, quando consciente de suas dificuldades ao se deparar com atividades comuns a outras crianças, frustra-se, desenvolvendo uma tendência a evitar ou rejeitar atividades simples (sejam elas motoras ou sensoriais) que exijam o contato com sensaçôes diversas, como brincar ou ir à escola. Portanto, é fundamental que a criança obtenha um desempenho bem-sucedido, pois com isso o senso de competência é reafirmado, o que estimula a criança a participar de brincadeiras e atividades cada vez mais complexas (BURKE; MAILLOUX, 2000; PAHRAM, 2001; DUARTE, 2005; BODISON et al., 2006; GRACIANI; MOMO; SILVESTRE, 2007; WHITE et al., 2007).

Dunn $(1997,1999)$ propôs a existência de uma interação entre a neurociência e os conceitos comportamentais e, a partir disso, elaborou um modelo de processamento sensorial pautado no conceito de modulação sensorial. A modulação sensorial refere-se à capacidade de regular e organizar a intensidade e natureza da resposta aos estímulos sensoriais. $\mathrm{Na}$ modulação sensorial, os processos neurofisiológicos envolvidos são a habituação (acomodação do estímulo) e a sensibilização (percepção do estímulo). Ambos ocorrem de acordo com o limiar neurológico de cada indivíduo - um alto limiar indica facilidade para a ocorrência da habituação, enquanto um baixo limiar indica facilidade para que ocorra a sensibilização. Quando há falhas nessa capacidade, ocorrem os chamados Transtornos de Processamento Sensorial (TPS) do tipo 1 - Transtornos de Modulação Sensorial (TMS) (DUARTE, 2005; REIKE; ANDERSON, 2009).

A partir desses pressupostos, Dunn (1997, 1999) elaborou um instrumento denominado Sensory Profile (perfil sensorial) para avaliação do processamento sensorial. O Sensory Profile mensura o quanto o processamento sensorial da criança facilita ou dificulta seu desempenho funcional, identificando diferentes subtipos de transtornos de modulação sensorial. Contudo, esse instrumento deve ser utilizado com cautela, uma vez que não existem normas brasileiras de desempenho (WHITE et al., 2007; MAGALHÃES, 2008; REIKE; ANDERSON, 2009).

No Sensory Profile, os limiares neurológicos são comparados ao padráo de resposta comportamental, que pode ser a favor do limiar (comportamento passivo) ou contra ele (comportamento ativo). Inicialmente, acreditava-se que haveria um contínuo entre hipo e hiper-respostas aos estímulos, com crianças atípicas localizando-se nas extremidades desse contínuo e os casos típicos se distribuindo na região central dele. Sabe-se hoje que os mecanismos de atenção e organização das respostas comportamentais são mais complexos e que podem ser observados basicamente três padróes de reação ao estímulo: a hiper-reação, a hiporreação e a busca sensorial. Também há casos em que tais padrôes se alternam: o chamado padrão flutuante de resposta. É importante lembrar que tais padróes costumam estar em equilíbrio, uma vez que todas as pessoas se encaixam em um dos padróes e a maioria funciona de forma adequada no ambiente. (DUNN, 1997, 1999; DUARTE, 2005; GRACIANI; MOMO; SILVESTRE, 2007; MAGALHÃES, 2008; REIKE; ANDERSON, 2009)

Quando cada um dos padróes citados anteriormente está em desequilíbrio, as crianças manifestam alguns comportamentos como: 
agressividade, irritabilidade, lentidão para compreender as explicaçóes ou realizar as açóes solicitadas, distraibilidade, comportamento explosivo quando solicitada a ficar quieta e dificuldades para manter-se quieta ou sentada. Muitas vezes, as crianças que apresentam esses comportamentos também apresentam baixo rendimento na escola e por isso são qualificadas de "devagar", "bagunceira", "preguiçosa" ou "burra", sendo que na verdade apresentam um transtorno de processamento sensorial (GRACIANI; MOMO; SILVESTRE, 2007; MAGALHÃES, 2008).

Dunn (1999), Gonçalves, Tonelotto e Ravanini (2000), Araújo, Mattos e Pastura (2005), Franco e Panhoca (2007), Rosin-Pinola, Del Prette e Del Prette (2007) e Graciani, Momo e Silvestre (2007) afirmam que aprender é uma função cognitiva e não somente uma cópia de atitudes sem significado. As aprendizagens formais transmitidas pela escola dependem essencialmente da integração do pensar, sentir, falar, ouvir e agir, influenciados pela ação constante de fatores internos (origem orgânica, cognitiva e emocional) e externos (origem social ou pedagógica) ao indivíduo.

Gonçalves, Tonelotto e Ravanini (2000) destaca ainda que o motivo de tamanha preocupação com o assunto reside no fato de o sucesso do indivíduo na sociedade estar inteiramente ligado à sua capacidade de aprender mas, segundo o senso comum, os problemas de escolaridade são definidos simplesmente pela incapacidade apresentada por um aluno de cumprir os conteúdos mínimos definidos como padrão para o seu grupo, sem que se reflita se tal condição é causada por fatores internos ou externos.

Segundo Araújo, Mattos e Pastura (2005), há grande dificuldade na definição de baixo desempenho escolar face aos inúmeros parâmetros utilizados para avaliar esse fenômeno como: pontuação abaixo do esperado para o coeficiente de inteligência (QI) em testes padronizados, baixo desempenho em termos absolutos (sem comparação com QI) em testes padronizados ou notas baixas em avaliaçóes das disciplinas. Algumas medidas tomadas com base em tais resultados são a alocação em turmas especiais, a repetência ou a suspensão.

Ainda segundo Araújo, Mattos e Pastura (2005), a existência de baixo desempenho escolar é prejudicial e custosa, tanto em termos financeiros quanto em termos pessoais - em virtude do sofrimento trazido para o aluno e para a família - levando à baixa autoestima e a dificuldades nas relaçôes interpessoais.

Estudos apontam que crianças com queixa de baixo desempenho escolar, quando comparadas às crianças com bom desempenho, apresentaram diferença estatisticamente significativa quanto à: a) produção: atividades de qualidade média; b) comportamento: baixa capacidade de organização, atenção, iniciativa, decisão, comunicação e interação espontânea; c) percepção: baixo senso de autoeficácia (MEDEIROS et al., 2003; OKANO et al., 2004; ROSIN-PINOLA; DEL PRETTE; DEL PRETTE, 2007; WHITE et al., 2007). Rosin-Pinola, Del Prette e Del Prette (2007) destaca ainda que, quando avaliadas por terceiros (colegas e professores), essas crianças foram mais negativamente avaliadas em termos de: interaçóes com seus pares, maior agressividade e baixa assertividade. Tais características são comuns também a crianças com TPS.

A autoeficácia dos estudantes, juntamente com outras crenças e atitudes em relação à aprendizagem, tem sido considerada forte preditor de desempenho acadêmico. A autoeficácia influencia o desempenho acadêmico e, ao mesmo tempo, é influenciada por ele, tendo implicações no desenvolvimento da criança como um todo (MEDEIROS et al., 2003; OKANO et al., 2004).

Medeiros et al. (2003) observou que crianças com baixo desempenho escolar realizam mais atividades ao longo do dia do que as crianças com rendimento escolar satisfatório. Essas mesmas crianças realizam tais atividades com um padrão médio de qualidade e interagem de forma espontânea. Apesar disso, denotam poucos recursos de organização e atenção para aprimorar a qualidade de suas produções e adequar seu padrão de interação.

Crianças com dificuldades de aprendizagem ou do desenvolvimento (frequentemente associadas a baixo rendimento escolar) geralmente apresentam dificuldades para processar informaçóes de um ou mais sistemas sensoriais (MAILLOUX; PAHRAM, 2001).

Quando uma criança apresenta baixo desempenho escolar em consequência de um processamento sensorial deficiente, vários fatores podem estar atuando: uma resposta mal modulada às sensaçóes ou o registro ou interpretação errônea da sensação (DUARTE, 2005).

O presente estudo visa observar se o processamento sensorial está diretamente ligado ao rendimento escolar e de que forma essa relação se manifesta.

\section{Metodologia}

\subsection{Método}

Este é um estudo transversal de análise descritiva. Os estudos transversais (também chamados "seccionais") investigam prevalências objetivando 
relacionar dois eventos entre si - neste trabalho, a qualidade do processamento sensorial e o desempenho escolar de crianças em idade de alfabetização. Quando os estudos seccionais, têm por finalidade a descriçáo dos achados durante a pesquisa e são caracterizados como de análise descritiva (PEREIRA, 1997).

\subsection{Caracterização dos participantes}

Foi utilizada amostra por conveniência, retirada de uma turma de primeira série do ensino fundamental de uma escola da rede municipal de ensino de Maceió, AL, e o parâmetro utilizado foi a média das notas obtidas pelas crianças nos primeiro e segundo bimestres do ano letivo de 2009

A turma selecionada possuía 24 alunos (tamanho da amostra $=24$ ), com idade entre 6 e 8 anos. Dentre os estudantes, apenas 7 participaram da pesquisa. Pais de 6 crianças se recusaram a participar e os pais ou responsáveis por 9 crianças não compareceram à escola quando chamados para serem informados a respeito do estudo. Dois dos estudantes mudaram de escola durante o período de coleta de dados.

Nenhuma das crianças que participou da pesquisa apresentava diagnóstico médico de quaisquer condiçóes que acarretassem em atrasos ou transtornos do desenvolvimento e frequentam um mínimo de $75 \%$ da carga horária exigida pela escola.

\subsection{Procedimentos para coleta dos dados}

A coleta de dados ocorreu entre os meses de maio e agosto de 2009, através da aplicação do Sensory Profile e de um questionário socioeducacional. O questionário continha perguntas referentes a informaçóes que, apesar de não estarem diretamente relacionadas a alteraçóes sensoriais, poderiam interferir tanto no processamento sensorial da criança quanto em seu desempenho escolar. As perguntas relacionaram-se ao nível de escolaridade materna, à prática de atividades físicas pelas crianças e ao histórico de repetência escolar, além do registro da idade da criança e de sua data de nascimento. Tanto o Sensory Profile quanto o questionário socioeducacional foram respondidos pelas mães das crianças.

O Sensory Profile (perfil sensorial), criado por Winnie Dunn em 1999, após pesquisa envolvendo mais de 1.200 crianças americanas com e sem transtornos do desenvolvimento, entre os anos de 1993 e 1999, é um dos instrumentos mais utilizados atualmente no que se relaciona à integração sensorial
(DUNN, 1999; DUARTE, 2005; MAGALHÁES, 2008).

O Sensory Profile é um teste de triagem, criado com o propósito de unir aspectos funcionais com os padróes de processamento sensorial da criança, de forma a possibilitar a avaliação das possíveis contribuiçôes do processamento sensorial para os padrôes de performance diária da criança, além de informar se suas tendências de resposta ao estímulos dos diversos sistemas sensoriais favorecem ou dificultam seu desempenho funcional. Na clínica terapêutica ocupacional, o instrumento deve ser combinado a evoluçóes, observaçóes e relatórios, no intuito de identificar transtornos de processamento sensorial (DUNN, 1999; DUARTE, 2005).

O Sensory Profile deve ser respondido por pais ou cuidadores, que mensuram a frequência com que ocorrem determinados comportamentos (sempre, frequentemente, às vezes, ocasionalmente ou nunca). $\mathrm{O}$ instrumento lista 125 comportamentos agrupados em três seçóes principais: processamento sensorial, modulação e respostas comportamentais e emocionais. Além de indicar o padrão de resposta, o instrumento a classifica em uma de três categorias possíveis: Desempenho típico, Diferença provável e Diferença clara. Para que os escores sejam calculados, é atribuído um valor aritmético a cada frequência citada: nunca $=5$, ocasionalmente $=4$, às vezes $=3$, frequentemente $=2$ e sempre $=1$. Quanto menor for o escore do item ou sessão, maior a indicação de alteração. Dessa forma, os escores mais altos se enquadram na faixa de Desempenho típico, enquanto os escores mais baixos estão localizados na faixa de Diferença clara. Os escores medianos serão localizados em Diferença provável, mas não são indicadores isolados de alteraçóes no processamento ou modulação sensorial (DUNN, 1999; DUARTE, 2005).

As pesquisadoras passaram por treinamento para a aplicação do instrumento. Durante as entrevistas foram utilizadas fichas, com o objetivo de auxiliar os pais ou responsáveis a identificar claramente a frequência dos comportamentos pesquisados.

\subsection{Procedimento para análise dos dados}

Os dados gerados pelo Sensory Profile foram cruzados com as médias das crianças em todas as disciplinas oferecidas pela escola: Português, Matemática, Ciências, História, Geografia, Religião e Artes. A escola não oferece aulas de Educação Física. 
O conceito de bom desempenho escolar e mau desempenho escolar foi desenvolvido de acordo com a média exigida pela escola: todas as notas iguais ou acima de 6,0 são consideradas suficientes para a aprovação (bom desempenho escolar), enquanto as notas abaixo de 6,0 são consideradas insuficientes (baixo desempenho escolar).

\section{Resultados}

A amostra estudada foi composta por 6 indivíduos do sexo feminino $(85,8 \%)$ e 1 indivíduo do sexo masculino (14,2\%), com idade entre 6 anos e 11 meses e 7 anos e 11 meses, resultando numa média de idade de 7 anos e 3 meses.

Apenas uma criança $(14,2 \%)$ apresentou desempenho típico em todos os fatores e seçóes.

A Figura 1 mostra que o fator com maior quantidade de Desempenho típico (85,8\%) é o fator 9 (Percepção/motor fino). $O$ fator que mostra a menor quantidade de Desempenho típico é o fator 1
(Procura sensorial), com apenas $28,4 \%$ de crianças apresentando-se dentro da normalidade nesse fator.

O fator 3 (Baixa resistência/tônus) é o que apresenta maior quantidade de crianças apresentando Diferença clara (56,8\%), seguido pelos fatores 1 (Procura sensorial) e 7 (Sensibilidade sensorial), ambos apresentando $42,6 \%$ de crianças com alteraçốes.

Em relação às áreas de processamento sensorial, a maior porcentagem de Desempenho típico é encontrada dentro do processamento visual $(56,8 \%)$, enquanto o processamento vestibular apresenta a menor porcentagem de Desempenho típico $(28,4 \%)$. As maiores quantidades de Diferenças claras de processamento foram encontradas dentro do processamento das informaçôes vestibular e oral (42,6\%, Figura 2).

$\mathrm{Na}$ Figura 3, referente à modulação sensorial, se observa que $85,8 \%$ das crianças estudadas apresentaram Desempenho típico referente à modulação da entrada sensorial, afetando as respostas emocionais. Apenas uma criança (14,2\%) apresenta

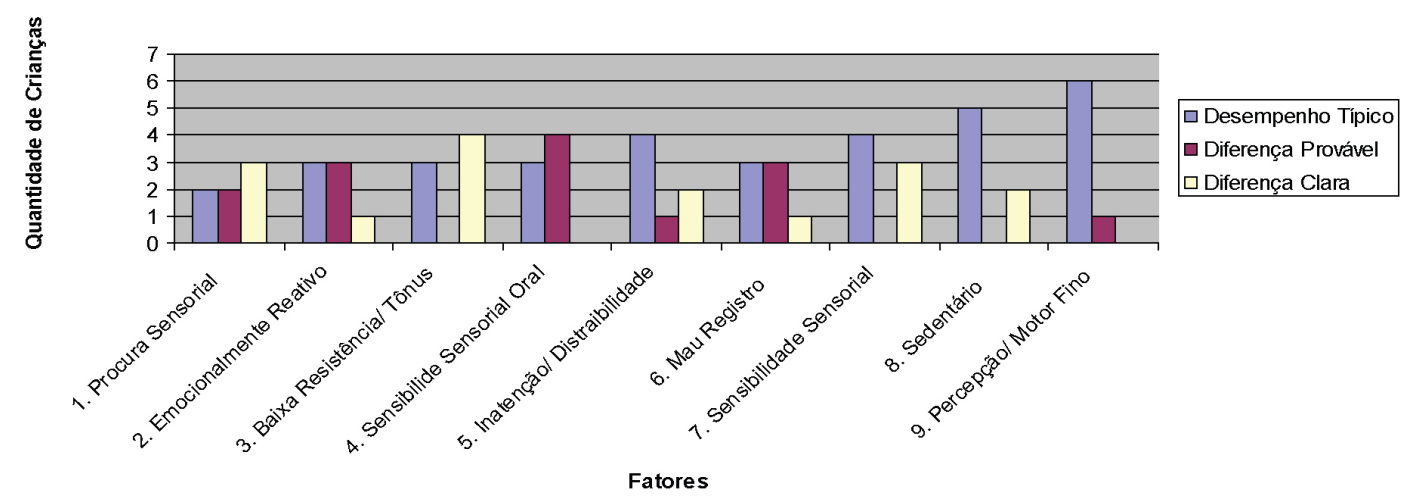

Figura 1. Resposta por Fator $\times$ Níveis de Desempenho Sensorial.
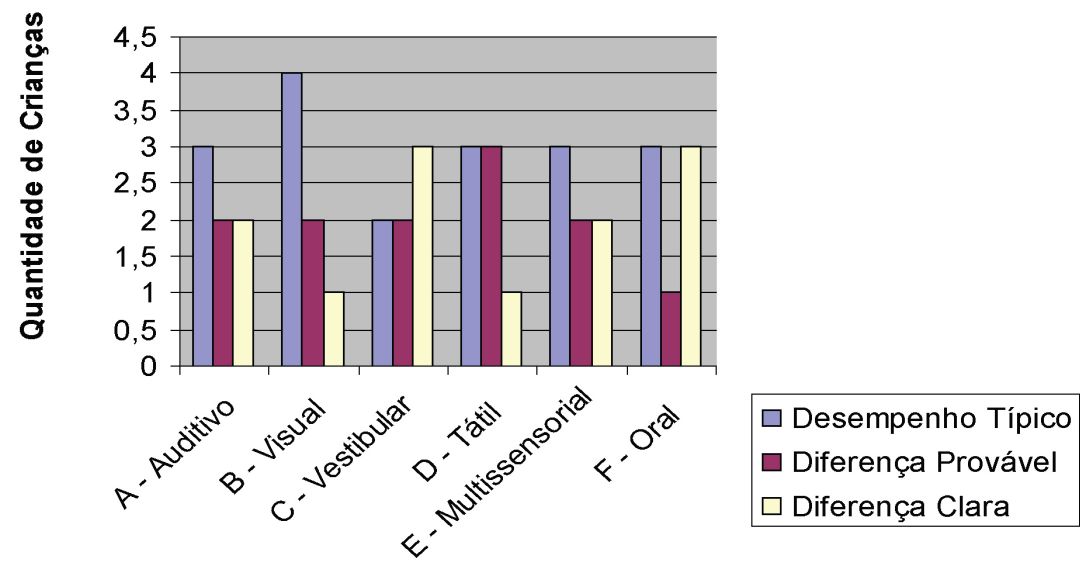

Processamento Sensorial

Figura 2. Processamento Sensorial $\times$ Níveis de Desempenho Sensorial. 
Desempenho típico referente à modulação relacionada à posição do corpo no espaço, dado que pode estar relacionado ao baixo índice de Desempenho típico do processamento vestibular, bem como ao fato de que nenhuma das crianças realizava atividades físicas, dentro ou fora da escola. A instituição também não possuia parquinho, que poderia fornecer a estimulação vestibular necessária para aprimoramento do processamento das informaçóes vestibulares.

Os itens que apresentaram maior porcentagem de alteraçôes (pontuação $=1$, equivalente à resposta Sempre) foram: item 24 (Procura tanto movimento que isso interfere em sua rotina diária), item 63 (Procura certos sabores/cheiros), item 69 (Parece ter músculos fracos), item 72 (Apóia-se para dar suporte ao corpo) e item 83 (Procura brincadeiras de cair, sem se preocupar com a sua segurança).

Todos os itens citados são indicativos de alto limiar neurológico e três deles (itens 69, 72 e 83) relacionam-se a informaçôes quanto à posição do corpo no espaço. O item 24 está relacionado a informaçôes gustativas e olfativas, enquanto o item 63 está relacionado a informaçóes sobre o nível de movimento. Esses mesmos itens estão distribuídos por quatro seçôes: Processamento vestibular (item 24), Processamento oral (item 63), Processamento sensorial relacionado a tônus/resistência (itens 69 e 72) e Modulação sensorial relacionada à posição do corpo no espaço (item 83). Tais dados sugerem dificuldade no processamento ou interpretação das informaçôes vestibulares e somatossensoriais.

Relacionando-se os fatores sensoriais às médias obtidas pelas crianças, observa-se que as que apresentavam Desempenho típico nos fatores 1 (Procura sensorial), 2 (Emocionalmente reativo), 3 (Baixa resistência/tônus), 4 (Sensibilidade sensorial oral) e 5 (Inatenção/distraibilidade) alcançaram médias superiores às crianças que apresentaram Diferença clara nos mesmos fatores. O inverso pode ser notado nos itens 7 (Sensibilidade sensorial) e 8 (Sedentário) (Figura 4).

Observando-se as médias das crianças de acordo com seu nível de desempenho sensorial relacionado ao processamento sensorial (Figura 5), percebe-se que

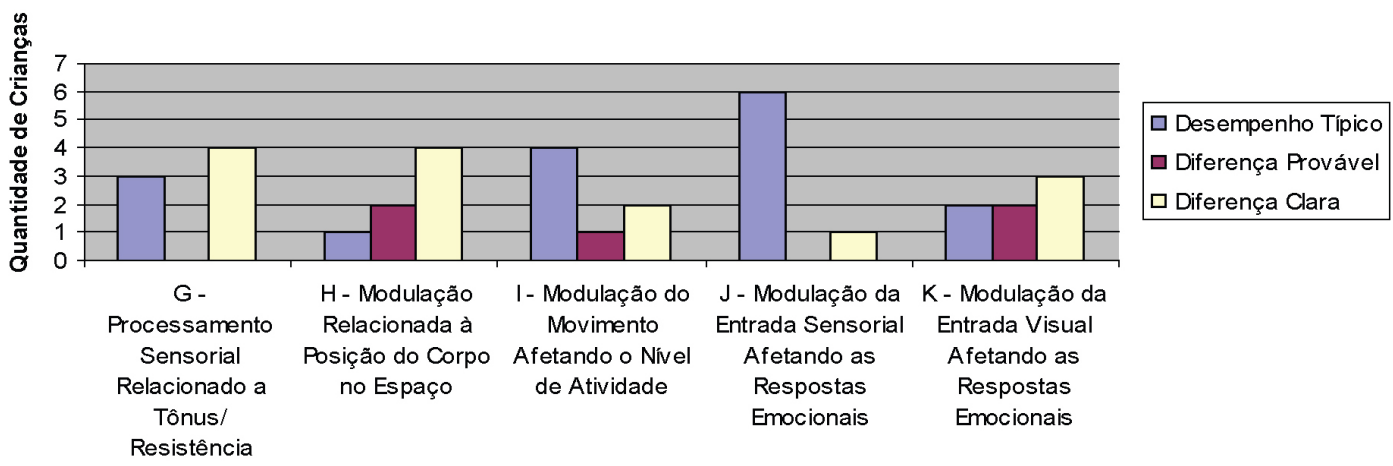

Seções de Modulação

Figura 3. Modulação Sensorial $\times$ Níveis de Desempenho Sensorial.

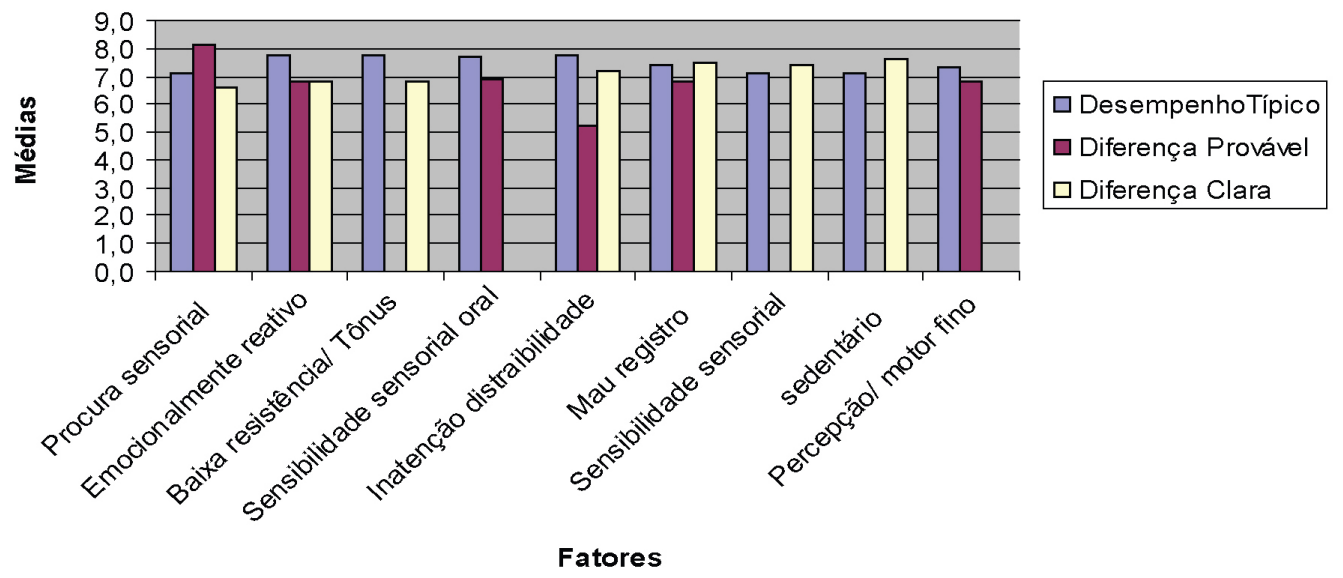

Figura 4. Distribuição das notas por fator. 


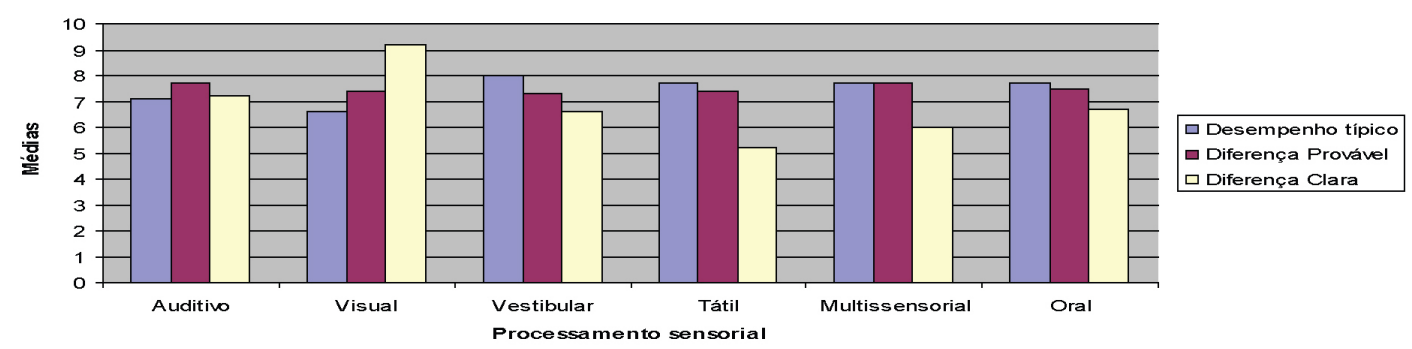

Figura 5. Desempenho escolar relacionado ao processamento sensorial.

crianças com Desempenho típico e Diferença provável apresentam médias maiores que as crianças com Diferença clara em todos os tipos de processamento, com exceção do processamento visual, (onde a maior média foi atingida pelo grupo que apresenta Diferença clara nesse tipo de processamento). Tal achado pode ser justificado, considerando que o grupo de crianças apresentando Diferença clara nos comportamentos referentes ao processamento visual foi formado por apenas um indivíduo - que apresentou as melhores notas em todas as disciplinas.

Em todas as disciplinas, as melhores médias estavam acompanhadas de um elevado número de comportamentos localizados no Desempenho típico em todas as seçôes e fatores, enquanto que as piores notas estavam acompanhadas do menor número de Desempenho típico, associado a um elevado número de comportamentos apresentando Diferença clara. Apesar disso, a única criança da turma a apresentar $100 \%$ de Desempenho típico em seus comportamentos foi o único menino da amostra, que apresentava notas medianas (média de 6,7 pontos por disciplina).

Em contrapartida, a criança que apresentou as maiores notas (em todas as disciplinas), apresentou Diferença clara apenas no processamento visual, de forma que os outros processamentos e fatores se apresentaram de acordo com o Desempenho típico (excetuando-se o fator 1 - Procura sensorial -, no qual foi identificado um comportamento de Diferença provável). Já a criança com os piores resultados (em todas as disciplinas) apresentou Desempenho típico apenas nos fatores 7 (Sensibilidade sensorial), 8 (Sedentário) e 9 (Percepção/motor fino). No que se refere ao processamento sensorial, a mesma criança apresentou comportamento condizente com Desempenho típico apenas nos processamentos visual e auditivo.

Em relação ao questionário socioeducacional, foi observado que nenhum dos indivíduos da amostra apresentava histórico de repetência bem como nenhum deles realizava atividades físicas dentro da escola ou fora dela. No que se referia à escolaridade materna, apenas a mãe de uma criança $(14,2 \%)$ tinha ensino médio completo. Das 6 máes restantes, $3(42,9 \%)$ haviam estudado somente até a quarta série do ensino fundamental, enquanto outras $3(42,9 \%)$ haviam estudado até a oitava série do ensino fundamental.

\section{Discussão}

Os dados encontrados diferem da maioria das informações presentes na revisão de literatura, provavelmente devido a dois fatores correlacionados, sendo o primeiro a amostra por conveniência e o segundo, a possibilidade de apenas as pessoas responsáveis por crianças com suspeita de alteraçóes terem se voluntariado para participar da pesquisa.

Em geral, a literatura mostra que há preponderância do sexo masculino sobre o feminino no que se refere ao número de casos de baixo desempenho escolar, numa proporção que varia de 2:1 a 3:1 (ARAÚJO; MATTOS; PASTURA, 2005). Apesar desses dados, a criança com melhor rendimento escolar dentre os indivíduos estudados era também a única criança do sexo masculino.

Embora Miller-Kuhaneck (2007) afirme que crianças com processamento sensorial pobre tenham dificuldades para funcionar adequadamente em sala de aula, foi observado que metade das crianças apresentando indícios de processamento sensorial pobre apresentava rendimento escolar satisfatório (médias 7,5 e 8,0 pontos por disciplina), um quarto das crianças do mesmo grupo apresentava baixo rendimento escolar (média de 5,2 pontos por disciplina) e um quarto apresentava rendimento mediano (média de 6,8 pontos por disciplina). Já dois terços das crianças com indícios de processamento sensorial adequado apresentaram desempenho escolar satisfatório (médias de 7,2 e 9,2 pontos por disciplina), enquanto a criança que apresentou todos os itens de processamento sensorial na faixa de Desempenho típico teve rendimento escolar mediano: cerca de 
6,7 pontos por disciplina (a segunda média mais baixa de toda a amostra).

Um dos dados encontrados, que converge com as informaçôes colhidas na revisão bibliográfica, foi a alta incidência de alteraçôes vestibulares interferindo no desempenho escolar das crianças (FRANCO, 2007; GRACIANI; MOMO; SILVESTRE, 2007).

Em estudo realizado por Franco e Panhoca (2007), observou-se que a disfunção vestibular infantil pode afetar consideravelmente a habilidade de comunicação e o desempenho escolar. Durante seu estudo, que comparou crianças com e sem dificuldades escolares, foi observado que apenas $31,6 \%$ das crianças do primeiro grupo apresentaram exame vestibular normal, contra $74,2 \%$ do grupo sem dificuldades de aprendizagem. Além disso, foram encontradas alterações vestibulares de origem irritativa periférica num total de $68,4 \%$ entre as crianças com dificuldades escolares e em um total de 25,8\% para crianças sem dificuldades escolares.

A importância de tais dados em um trabalho que relaciona integração sensorial e desempenho escolar se deve ao fato de que a postura, o equilíbrio e a coordenação motora (funçôes reguladas pelo sistema vestibular) têm sido reconhecidos como bases importantes para a aprendizagem, inclusive $\mathrm{da}$ linguagem falada e escrita (FRANCO; PANHOCA, 2007).

\section{$\mathrm{O}$ autor destaca que:}

[...] as dificuldades para realizar movimentos coordenados e a noção imprecisa da posição espacial de si mesmo e dos objetos transtornam a aprendizagem em crianças com labirintopatias. A falta de aptidão para praticar alguns movimentos físicos, a adoção de posiçóes cefálicas anormais durante a escrita, as sensações destorcidas do tamanho, do peso e da estrutura corporal, da dimensão dos objetos distantes ou das relaçóes espaciais prejudicam o adequado contato da criança com o meio ambiente, influenciando negativamente seu desenvolvimento físico e psíquico. Tais crianças, não raramente, são inquietas devido à constante procura de posições de conforto e segurança, o que as leva à dificuldade de concentração e à dispersão. Podem não gostar de brincar, andar de bicicleta (ou de tirar o apoio das rodas laterais), de andar sobre o muro ou guia de sarjeta, de pular corda ou amarelinha, de usar os brinquedos de playground. (FRANCO; PANHOCA, 2007, p. 804).

Franco e Panhoca (2007), por fim, acrescenta que queixas inespecíficas como mudança súbita de comportamento, agitação, perturbação do sono, cefaleia, medo de altura, medo de escuro, quedas, náuseas e vômitos devem ser valorizados, já que podem ser evidências de problemas que comprometerão o rendimento escolar da criança e todo o seu processo de desenvolvimento. Esses sintomas são decorrentes de distúrbios do sistema vestibular e de suas relaçóes com o sistema nervoso central, visão e propriocepção, além de vários outros órgãos e sistemas localizados, muitas vezes, a distância do labirinto

Davies e Gavin (2007) e White et al. (2007) advertem que a teoria de integração sensorial, suas disfunçôes e possíveis abordagens, é hoje uma das mais estudadas áreas da Terapia Ocupacional e que, apesar disso, alguns autores ainda consideram os achados discutíveis.

\section{Limitações do estudo}

Embora o presente estudo traga rica discussão acerca da relação entre a qualidade do processamento sensorial e o desempenho escolar de crianças em fase de alfabetização, a amostragem por conveniência e a impossibilidade de igualar o número de indivíduos da amostra quanto a gênero impedem que os achados desta pesquisa possam ser generalizados. Dessa forma, é de extrema importância a continuidade de pesquisas que se proponham a discutir a relação processamento sensorial-desempenho escolar, utilizando amostras mais numerosas e melhor definidas, para que entáo seus resultados possam ser generalizados. É pertinente destacar ainda a importância de estudos que apresentem a análise qualitativa dessa relação, para que seja possível uma melhor compreensão e atuaçáo sobre os diferentes transtornos de aprendizagem e de integração sensorial.

\section{Conclusões}

Os achados sugerem que embora exista relação entre o processamento sensorial e o desempenho escolar, a qualidade do processamento não é o único preditor do desempenho escolar. Ainda que a presente pesquisa apresente dados importantes, o caráter da amostra (por conveniência) afeta seu poder estatístico e impede a generalizaçáo dos achados, havendo a necessidade da execução de trabalhos mais aprofundados a respeito da relação entre o processamento sensorial e o desempenho escolar das crianças. Para tais pesquisas, é sugerido o uso de outros protocolos de avaliação associados ao perfil sensorial, como observações clínicas. 


\section{Referências}

ARAÚJO, A. P. Q. C.; MATTOS, P.; PASTURA, G. M. C. Desempenho escolar e transtorno do déficit de atençáo e hiperatividade. Revista de Psiquiatria Clínica, São Paulo, v. 32, n. 6, p. 324-329, 2005.

AYRES, A. J. Sensory Integration and the Child: Understanding Hidden Sensory Challenges. New York: Editora WPS Publish, 2005.

BODISON, S. et al. Sensory integration: It's not just for children. Sensory Integration Special Interest Section Quarterly, Bethesda, v. 29, n. 4, p. 1-4, 2006.

BURKE, J. P.; MAILLOUX, Z. A recreação e a Abrangência da Integração Sensorial. In: PARHAM, L. D.; FAZIO, L. S. A recreação e a terapia ocupacional pediátrica. São Paulo: Editora e Livraria Santos, 2000. p. 112-125.

DAVIES, P. L.; GAVIN, W. J. Validating the diagnosis of sensory processing disorders using EEG technology. American Journal of Occupational Therapy, New York, v 61, p 176-189, 2007. http://dx.doi.org/10.5014/ajot.61.2.176

DUARTE, L. M. M. Investigaçâo do perfil sensorial da clientela pediátrica na faixa etária dos 3 a 10 anos de idade da unidade de terapia ocupacional - U.T.O., utilizando o sensory profile. 2005. 80 f. Monografia (Graduação em Terapia Ocupacional)-Faculdade de Terapia Ocupacional de Alagoas, Universidade Estadual de Ciências da Saúde de Alagoas, 2005.

DUNN, W. The Impact of Sensory Processing Abilities on the Daily Lives of Young Children and Their Families: A Conceptual Model. Infants and Young Children, Frederick, v. 9, n. 4, p. 23-35, 1997. http://dx.doi. org/10.1097/00001163-199704000-00005

DUNN, W. Sensory Profile: User's manual. New York: The Psychological Corporation, 1999.

FRANCO, E. S.; PANHOCA, I. Avaliação otoneurológica em crianças com queixa de dificuldades escolares: pesquisa da função vestibular. Revista Brasileira de Otorrinolaringologia, São Paulo, v. 73, n. 6, p. 803-815, 2007. http://dx.doi.org/10.1590/ S0034-72992007000600012

GONÇALVES, V. M. G.; TONELOTTO, J. M. F.; RAVANINI, S. G. Semiologia neurológica numa população de escolares da primeira série do ensino fundamental. Arquivos de Neuro-Psiquiatria, São Paulo, v. 58, n. 1, p. 112-118, 2000. http://dx.doi.org/10.1590/ S0004-282X2000000100017

GRACIANI, Z.; MOMO, A. R. B.; SILVESTRE, C. $O$ processamento sensorial como ferramenta para educadores: Facilitando o processo de aprendizagem. São Paulo: Memnom Edições Gráficas, 2007.
MEDEIROS, P. C. et al. O senso de auto-eficácia e o comportamento orientado para aprendizagem em crianças com queixa de dificuldade de aprendizagem. Estudos em Psicologia, Natal, v. 8, n. 1, p. 93-105, 2003. http://dx.doi. org/10.1590/S1413-294X2003000100011

MAGALHÃES, L. C. Integração Sensorial - Uma abordagem específica de Terapia Ocupacional. In: REZENDE, M. B. Intervençôes em Terapia Ocupacional. Belo Horizonte: Editora UFMG, 2008. p. 45- 67.

MAILLOUX, Z.; PAHRAM, L. D. Sensory integration. In: CASE-SMITH, J. Occupational Therapy for children. New York: Editora Mosby, 2001. p. 329-381.

MILLER-KUHANECK, H. et al. Development of the Sensory Processing Measure-School: Initial studies of reliability and validity. American Journal of Occupational Therapy, New York, v. 61, p. 170-175, 2007. http://dx.doi. org/10.5014/ajot.61.2.170

OKANO, C. B. et al. Crianças com dificuldades escolares atendidas em programa de suporte psicopedagógico na escola: avaliação do autoconceito Psicologia: Reflexão e Crítica, Porto Alegre, v. 17, n. 1, p. 121-128, 2004. http://dx.doi.org/10.1590/S0102-79722004000100015

OLIVEIRA, C. B. O perfil psicomotor de crianças cursando a primeira série do ensino fundamental e a sua interferência na aprendizagem escolar. 2005. 68 f. Monografia (Graduação em Terapia Ocupacional)-Faculdade de Terapia Ocupacional de Alagoas, Universidade Estadual de Ciências da Saúde de Alagoas, Maceió, 2005.

PEREIRA, M. G. Epidemiologia: Teoria e Prática. Rio de Janeiro: Guanabara Koogan. 1997.

REIKE, E. F.; ANDERSON, D. Adolescent/Adult Sensory Profile and obsessive-compulsive disorder. American Journal of Occupational Therapy, New York, v. 63, p. 138-145, 2009. http://dx.doi.org/10.5014/ajot.63.2.138 ROSIN-PINOLA, A. R.; DEL PRETTE, Z. A. P.; DEL PRETTE, A.. Habilidades sociais e problemas de comportamento de alunos com deficiência mental, alto e baixo desempenho acadêmico. Revista Brasileira de Educação Especial, Marília, v. 13, n. 2, p. 239-156, 2007.

WATLING, R. L.; DEITZ, J.; WHITE, O. Comparison of Sensory Profile scores of young children with and without autism spectrum disorders. American Journal of Occupational Therapy, New York, v 55, p. 416-423, 2001. http://dx.doi.org/10.5014/ajot.55.4.416

WHITE, B. P. et al. An examination of the relationships between motor and process skills and scores on the Sensory Profile. American Journal of Occupational Therapy, New York, v. 61, p. 154-160, 2007. http://dx.doi.org/10.5014/ ajot.61.2.154

\section{Contribuição dos Autores}

As autoras trabalharam conjuntamente na concepção, desenvolvimento e redação do texto, sendo Alessandra Dounis orientadora da pesquisa. 